\title{
REFLEXÕES E CONCEPÇÕES DE UMA PROFESSORA EM RELAÇÃO À ESTATÍSTICA, A PARTIR DE FORMAÇÃO BASEADA NO ENSINO REMOTO
}

\section{REFLECTIONS AND CONCEPTIONS OF A TEACHER IN RELATION TO STATISTICS BASED ON TRAINING BASED ON REMOTE TEACHING}

\author{
Danilo do Carmo de Souza ${ }^{1}$; Marisa Lima de Vasconcelos ${ }^{2}$; Juscileide Braga de Castro ${ }^{3}$
}

\begin{abstract}
RESUMO
A Base Nacional Comum Curricular indica o estudo dos conceitos estatísticos desde os primeiros anos do Ensino Fundamental, já que essa área implica na formação de um indivíduo crítico frente às informações. A aprendizagem da Estatística está ligada à formação do professor, que deve possuir conhecimentos procedimentais e metodológicos. Desse modo, buscando auxiliar nesse processo, a Rede Educação Matemática Nordeste (REM-NE), ofertou um curso de formação de professores, intitulado "Matemática \#COmVIDa", distribuído em quatro módulos, contendo atividades contextualizadas sobre o Ensino de Estatística durante a pandemia da Covid-19. Este artigo tem como objetivo analisar as reflexões e concepções de uma professora dos anos iniciais em relação aos conceitos estatísticos, durante a vivência do primeiro módulo deste curso, onde foram trabalhados tais conceitos. A pesquisa possui abordagem qualitativa do tipo descritiva, pois descrevemos os fatores e as variáveis envolvidas no fenômeno estudado. A metodologia adotada é a observação sistemática, feita por meio do acompanhamento das aulas, que foram gravadas e transcritas. Os resultados mostram que a professora superou as dificuldades atreladas à concepção e caracterização de variável estatística, construção, leitura e interpretação de informações contidas em gráficos e tabelas, além de levantar indícios sobre medidas de tendência central. Nesse sentido, a formação oportunizou reflexões de aplicabilidade cotidiana dos conceitos estatísticos, desmistificando essa área do conhecimento como restrita a uma pequena parcela da população. Destarte, inferimos que o curso contribuiu positivamente para a formação da professora, e que esse tipo de iniciativa gera grande impacto na formação continuada e no desenvolvimento profissional docente.
\end{abstract}

Palavras-chave: Ensino de Estatística; Formação de professores; Ensino remoto.

\footnotetext{
${ }^{1}$ Mestre em Educação pela Universidade Federal do Ceará (UFC). Professor da Educação Básica na Prefeitura Municipal de Fortaleza (PMF). Fortaleza, Ceará, Brasil. Rua Bento Gonçalves, 700, bloco 17 apartamento 104, Novo Mondubim, Fortaleza, Ceará, Brasil, CEP: 60763-832. E-mail: danilo.carmo@educação.fortaleza.ce.gov.br.

(1) ORCID iD: https://orcid.org/0000-0003-2111-4974.

${ }^{2}$ Graduanda em Licenciatura em Matemática pela Universidade Federal do Ceará (UFC), Fortaleza, Ceará, Brasil, Rua Espírito Santo, 662, Bela Vista, CEP: 60440775. E-mail: marisamatufc@ gmail.com.

(1) ORCID iD: https://orcid.org/0000-0002-0873-4928.

${ }^{3}$ Doutora em Educação pela Universidade Federal do Ceará (UFC). Professora da Faculdade de Educação da UFC (FACED/UFC). Professora do Programa de Pós-Graduação em Ensino de Ciências e Matemática do IFCE (PGECM/IFCE), Fortaleza, Ceará, Brasil. Rua Waldery Uchoa, 01 - Benfica - Fortaleza - CE. CEP 60020-110 E-mail: juscileide@ virtual.ufc.br.

(1) ORCID iD: https://orcid.org/0000-0002-6530-4860.
} 


\begin{abstract}
The National Common Curricular Base indicates the study of statistical concepts since the first years of Elementary School, as this area implies the formation of a critical individual in regard to information. The statistical learning is linked to the teacher training, who must have procedural and methodological knowledge. Therefore, seeking to assist in this process, the Northeast Mathematical Education Network (REM-NE), offered a teacher training course, entitled "Mathematics \#COmVIDa", distributed in four modules containing contextualized activities on the Teaching of Statistics during the Covid-19 pandemic. This article aims to analyze the reflections and conceptions of a teacher from the early years in relation to statistical concepts, during the experience of the first module of this course, in which the statistical concepts were worked on. The research has a descriptive qualitative approach, as we describe the factors and variables involved in the studied phenomenon. The methodology adopted is the systematic observation, made through the classes monitoring, which were recorded and transcribed. The results show that the teacher overcame the difficulties linked to the conception and characterization of the statistical variable, construction, reading and interpretation of information contained in graphs and table charts, in addition to raising evidence about measures of central tendency. In this sense, the training provided reflections on the daily applicability of statistical concepts, demystifying this area of knowledge as restricted to a small portion of the population. Thus, we infer that the course contributed positively to teacher training and this type of initiative has a great impact on continuing education and professional teacher development.
\end{abstract}

Keywords: Teaching Statistics; Teacher training; Remote teaching. 


\section{Introdução}

Os resultados das avaliações em larga escala da aprendizagem dos conteúdos escolares, como é o caso do Sistema de Avaliação da Educação Básica (SAEB), apontam que os estudantes possuem dificuldades com a Matemática (BRASIL, 2019).

Em relação aos anos iniciais do Ensino Fundamental, os resultados de 2017 mostram que 69,4\% desses estudantes não são capazes de interpretar dados em: tabela simples; gráficos de colunas duplas; gráficos de setores; comparar dados representados pelas alturas de colunas presentes em um gráfico e reconhecer o gráfico de linhas correspondente a uma sequência de valores ao longo do tempo (BRASIL, 2019).

Ao analisar a Base Nacional Comum Curricular (BNCC), documento de caráter normativo para as escolas brasileiras, verifica-se que estas habilidades estão relacionadas à unidade temática Probabilidade e Estatística (BRASIL, 2017). Destarte, a construção e a interpretação de informações contidas em gráficos e em tabelas são essenciais para a compreensão do contexto social, político e econômico (BATANERO, 2001; CASTRO, 2012; CAZORLA et al, 2017; BRASIL, 2017).

As dificuldades verificadas em estudantes podem estar atreladas a diversos fatores, entre eles: a precariedade na formação inicial e continuada de professores que ensinam matemática, as condições cognitivas dos estudantes, os tipos de recursos didáticos e as metodologias aplicadas em sala de aula.

De acordo com Pontes e Castro (2020), a formação inicial de professores que ensinam matemática, ou seja, aqueles que atuam nos anos iniciais do Ensino Fundamental, costuma deixar lacunas conceituais em relação à Estatística e sua aplicabilidade, assim como, relacionadas às questões metodológicas.

Nesse sentido, a formação continuada tem sido uma alternativa para que estes professores possam sanar dúvidas, trocar experiências e potencializar aprendizagens. Dentre os diferentes formatos de formação continuada, Nacarato (2000) destaca a formação colaborativa, por tratar-se de uma proposta que visa a troca de conhecimentos e o aprimoramento de conhecimento conceitual e pedagógico.

Alguns autores (NACARATO, 2000; PONTE, 1998) destacam que a formação colaborativa pode potencializar o desenvolvimento profissional docente. $\mathrm{O}$ desenvolvimento profissional de professores pode implicar no domínio de três, quais 
sejam: do conteúdo, pedagógico do conteúdo e curricular (SHULMAN, 1986). Uma vez que um desses não esteja consolidado, haverá dificuldades por parte do docente em desenvolver o processo de ensino, acarretando em baixos resultados na aprendizagem.

Partindo dessas reflexões, a Rede Educação Matemática Nordeste (REM-NE) ofertou uma formação para professores, baseada na perspectiva colaborativa, intitulada "Matemática \#COmVIDa", distribuída em quatro módulos, contendo atividades contextualizadas sobre o ensino de Estatística durante a pandemia da Covid-19. Nesse contexto, este artigo tem como objetivo analisar as reflexões e concepções de uma professora dos anos iniciais em relação aos conceitos estatísticos.

Isso posto, esta pesquisa encontra-se organizada em cinco seções: os elementos introdutórios, aqui apresentados; o referencial teórico, que trata da formação docente e o ensino de estatística; os procedimentos metodológicos e o contexto da pesquisa; a análise e a discussão dos resultados e, por fim, tecemos as considerações finais.

\title{
Formação docente e o Ensino de Estatística: reflexões conceituais
}

O contexto de formação de professores tem sido foco permanente de estudos de diferentes autores a partir das perspectivas curriculares, metodológicas e conceituais. Esses processos visam refletir diretamente no trabalho em sala de aula, uma vez que possibilitam a abertura de reflexões por parte do próprio docente, alicerçados em suas atitudes, posturas e a forma que direciona sua ação docente. Desse modo, cabe salientar a existência de múltiplos ambientes formativos com características próprias, seja na formação inicial, contínua, continuada e desenvolvimento profissional. Para Passos et al. (2006, p. 195), o desenvolvimento profissional é um fenômeno dinâmico:

\begin{abstract}
Além do crescimento pessoal ao longo da vida, compreende também a formação profissional (teórico-prática) da formação inicial - voltada para a docência e que envolve aspectos conceituais, didático-pedagógicos e curriculares - e o desenvolvimento e a atualização da atividade profissional em processos de formação continuada após a conclusão da licenciatura. A formação contínua, portanto, é um fenômeno que ocorre ao longo de toda a vida e que acontece de modo integrado às práticas sociais e às cotidianas escolares de cada um, ganhando intensidade e relevância em algumas delas.
\end{abstract}

Segundo Ponte (1998) o termo “desenvolvimento profissional" emergiu na literatura educacional como forma de demarcar uma diferenciação entre seu princípio de formação e o denominado ensino tradicional. Para o autor, iniciativas tradicionais não se 
demonstram contínuas na formação docente, pois geralmente estão associadas a cursos, capacitações e treinamentos, os quais caracterizam num movimento externo aos anseios do sujeito, já que as necessidades formativas são pré-estabelecidas pelo formador e, por vezes, não correspondem àquelas presentes nos contextos e nas práticas do professor.

Ademais, compreende-se que o docente, ao inserir-se em espaços formativos que priorizam o processo de reflexividade, analisa sua prática baseado em estudos teóricos que permitam redimensionar a prática e (re)criar tarefas significativas para os contextos nos quais trabalha. Ponte (1998, p. 3) destaca que o objetivo do desenvolvimento profissional é "[...] tornar os professores mais aptos a conduzir um ensino da Matemática adaptado às necessidades e interesses de cada aluno e de forma a contribuir para a melhoria das instituições educativas, realizando-se pessoal e profissionalmente".

Contudo, Batanero (2001) destaca o fato de conteúdos estatísticos como parte integrante do currículo escolar de Matemática. Estas indicações estão presentes em documentos norteadores do currículo, como os Parâmetros Curriculares Nacionais (PCN), que indicam o Bloco de Conteúdo: Tratamento da Informação e a BNCC, que inclui as habilidades de estatística da Unidade Temática: Probabilidade e Estatística (BRASIL, 2017). Apesar de esses documentos indicarem a Estatística desde o Ensino Fundamental, isso não implica que sejam ensinados nos vários níveis da Educação.

Silva e Souza (2019) investigaram a formação de futuros professores dos anos iniciais acerca dos saberes docentes de conteúdos estatísticos, especificamente, saberes atrelados à construção, leitura e interpretação de gráficos. Trata-se de uma pesquisa de cunho qualitativo, na qual a coleta dos dados deu-se em dois momentos: discussões teóricas sobre Estatística e resolução de problemas envolvendo gráficos, planejadas no curso de formação inicial e posteriormente ministradas na escola.

Os resultados indicam reflexões teóricas e práticas das atividades. No campo conceitual, os licenciandos tiveram contato com diferentes tipos de gráficos (colunas, barras, linhas, pictograma, setores), intencionalidades dos gráficos, elementos, na leitura dos dados, sendo possível uma evolução quanto à análise e interpretação para além das informações dos gráficos. Assim, os autores apontam a aproximação dos licenciandos com situações associadas à realidade do cotidiano escolar e a busca pela ampliação de estratégias durante as intervenções com estudantes da Educação Básica. 
A pesquisa de Lemos (2019) objetivou apresentar que compreensão e desenvolvimento pedagógico e didático do conteúdo podem ser identificados em professores que lecionam do $1^{\mathrm{o}}$ ao $5^{\mathrm{o}}$ ano do Ensino Fundamental sobre medidas de tendência central. A coleta dos dados foi realizada através da aplicação de uma sequência de ensino composta de dez tarefas contendo situações acerca da Estatística.

As atividades foram organizadas a fim de apresentar um grau crescente de dificuldades, para que a cada nova tarefa trabalhada, necessitasse relembrar as estratégias utilizadas em situações anteriores, proporcionando uma reflexão dos conceitos e a construção de novas estratégias. Os protocolos de discussões demonstram que as lacunas identificadas no início da formação sobre média, moda e mediana, foram sendo superadas, embora os sujeitos ainda apresentarem dificuldade acerca desses conceitos. Contudo, a formação dá indícios do desenvolvimento profissional dos docentes a partir das mudanças conceituais, atitudes e concepções pedagógicas acerca da Estatística (LEMOS, 2019).

Magina et al., (2010) analisaram as concepções de estudantes e professores sobre o conceito de média. Para tanto, as autoras aplicaram um teste, composto de três situações-problemas a 287 sujeitos, distribuídos em: 54 alunos da $4^{\mathrm{a}}$ série e 47 estudantes da $5^{\text {a }}$ série do Ensino Fundamental; 61 estudantes iniciantes dentre os quais 82 estudantes concluintes do curso de pedagogia e 43 professores dos anos iniciais.

Excetuando-se o grupo de professores, todos os grupos confundem média com a adição dos valores ou ao valor máximo da amostra. Os resultados apontam evolução no entendimento do conceito de média em relação aos níveis de escolaridade, contudo algumas confusões ainda são identificadas entre o grupo de professores. Outra concepção errônea refere-se ao fato de que vários sujeitos mostraram acreditar que a média coincide com pelo menos um dos valores, evidenciando que, mesmo sujeitos que já concluíram a formação básica, não concebem as propriedades do conceito de média.

A seguir, destacamos os procedimentos metodológicos e o contexto da pesquisa.

\section{Procedimentos metodológicos e o contexto da pesquisa}

Essa pesquisa integra o projeto intitulado Mathematics Teacher's Professional Development and Teaching Statistics at Elementary and Middle School, executado de forma colaborativa pela Rede Educação Matemática Nordeste (REM-NE), composta por 
universidades distribuídas entre os estados do Ceará, Bahia, São Paulo, Pernambuco e Rio Grande do Norte. O objetivo principal do projeto supracitado é compreender as experiências de aprendizagem de professores que ensinam matemática na Educação Básica, visando seu desenvolvimento profissional e a promoção de métodos de ensino para o aprendizado equitativo dos alunos.

No Ceará, este projeto também está vinculado ao Programa Institucional de Bolsas de Iniciação Científica (PIBIC) da Universidade Federal do Ceará (UFC), cadastrado com o título: Desenvolvimento profissional de professores que ensinam Matemática e Estatística no Ensino Fundamental: como promover métodos de ensino para o aprendizado equitativo dos alunos?

No ano de 2020, em virtude da pandemia vivenciada pela crise sanitária causada pela COVID-19, a REM-NE promoveu a realização de uma formação de professores, de forma remota, denominado Matemática \#COmVIDa. A formação foi dividida em quatro módulos, totalizando $80 \mathrm{~h} / \mathrm{a}$, distribuídos entre aspectos conceituais, teóricos e práticos nas seguintes vertentes: conteúdos estatísticos; equidade e investigação nas aulas de matemática; exploração e vivência de um ciclo investigativo baseado no ciclo PPDAC ${ }^{4}$.

A formação foi realizada entre setembro e dezembro de 2020 e contou com a participação de 48 professores do Ensino Fundamental, sendo 29 dos anos iniciais e 19 dos anos finais, os quais se reuniam remotamente em encontros síncronos e assíncronos.

Considerando os diferentes sujeitos e contextos vivenciados ao longo dessa formação, neste artigo optamos por analisar as reflexões e as concepções de uma professora dos anos iniciais em relação aos conceitos estatísticos. A escolha dessa professora decorre da área de atuação dos autores, do interesse por investigar os conhecimentos que docentes dos anos iniciais possuem, a relevância na participação durante os encontros e por termos participado de todo seu processo formativo.

A referida professora possui graduação em Pedagogia, leciona no $1^{\circ}$ ano do Ensino Fundamental de uma escola pública no município de Campinas e, para garantir seu anonimato, será designada pelo pseudônimo de Maria.

\footnotetext{
${ }^{4}$ Refere-se "O ciclo investigativo envolve cinco fases: definição do problema; planejamento do ciclo investigativo (sistema de medição, amostragem e análise); coleta dos dados; análise e conclusão, da qual ocorrem as interpretações e a comunicação dos resultados.” (CASTRO, 2012, p. 47)
} 
Para a análise dos protocolos da professora, baseamo-nos na proposta de uma pesquisa descritiva. Para Rudio (2000, p. 69), na pesquisa descritiva “o pesquisador procura conhecer e interpretar a realidade, sem nela interferir para modificá-la”. Assim, o papel do pesquisador é analisar as estratégias empregadas na resolução das atividades, identificar as estruturas e modelos aplicados pelos sujeitos que estão por trás dos fragmentos de mensagens tornados em consideração.

A seguir, passaremos a discorrer sobre os resultados e a análise dos dados.

\section{Apresentação, Análise e Discussão dos Resultados}

A partir dos protocolos da docente, destaca-se o surgimento de categorias relacionadas à dimensão conceitual: [1] classificação de variável estatística; [2] leitura, interpretação e construção de gráficos e tabelas; [3] medidas de tendência central.

\section{Classificação de variável estatística}

Na Estatística a variável "é uma característica da população que assume diferentes valores ou categorias" (CAZORLA et al., 2017, p. 36), podendo ser: qualitativa (categórica) ou quantitativa (numérica). A BNCC indica a exploração de variáveis categóricas a partir do $1^{\circ}$ ano do Ensino Fundamental e a no $4^{\circ}$ ano, os estudantes precisam desenvolver pesquisas que contemplem variáveis categóricas e numéricas, como forma de desenvolver habilidades previstas (BRASIL, 2017).

Para conseguir desenvolver as habilidades previstas pela BNCC, os professores precisam ter domínio do conceito de variável, de sua classificação, da operacionalização e da relação dessas variáveis com as questões de pesquisa. Ao longo da formação, a professora Maria explica que está aprendendo a classificar e conceituar variável, tendo em vista que não lembra ter estudado variável, assim como outros conceitos estatísticos abordados ao longo dos encontros. Pontes e Castro (2020) explicam que a Estatística costuma ser pouco explorada na trajetória profissional docente, o que contribui com as dificuldades de explorá-la fora do contexto apresentado no livro didático.

Considerando as dificuldades e lacunas formativas dos professores, a formação buscou reflexões e vivências que contribuíssem para o conhecimento da estatística. Para isso, foi proposto um problema de investigação: “Quais as condições dos professores do 
processo formativo do REM-NE para desenvolver suas atividades profissionais no período de isolamento social?”. Os dados foram coletados junto a todos os cursistas que participavam da formação. Dentre esses dados, foram feitas perguntas relativas ao perfil dos professores (idade, formação, cidade onde atua), assim como do tipo de instrumento tecnológico mais utilizado para trabalhar e como era a adequação ao local de trabalho.

A atividade de análise permitiu que Maria e outros professores pudessem desenvolver a compreensão de variável. Essa compreensão foi importante não apenas para classificar, mas também para relacionar o tipo de variável usada com a questão de pesquisa (CAZORLA et al., 2017).

A docente justificou a análise que faria, indicando que, inicialmente, analisaria a variável quantitativa discreta, indicada pela idade em anos completos dos professores que participaram da pesquisa. Ela explica, textualmente, que "A variável quantitativa Idade em anos completos é discreta, mas quando ela é transformada em intervalos, por exemplo (22;30), ela apresenta um processo contínuo, portanto, configura-se numa variável quantitativa contínua” (informação textual retirada da atividade 2 - Módulo 1).

Verificamos a partir desse protocolo escrito e da interação de Maria nos encontros síncronos, que as discussões e a atividade de análise de dados contribuíram para que ela se apropriasse do conceito de variável, conseguindo ainda diferenciar o tipo de variável numérica envolvida (discreta e contínua).

Maria ainda consegue verificar e apontar outro tipo de variável na análise realizada: "podemos observar que a variável qualitativa nominal: percepção do espaço para o trabalho remoto dos professores aparece com um índice bem menor em relação à percepção desse espaço. Podemos concluir que os professores parecem não ter um espaço confortável para seu trabalho neste período remoto" (informação textual retirada da atividade 2 - Módulo 1 - professora Maria). Estas conclusões apontadas por Maria foram feitas a partir da análise de um gráfico de setores, contudo, chama atenção o fato de ela destacar o tipo de variável para fazer suas conclusões. Esse destaque pode ser atribuído aos conhecimentos e confiança adquiridos ao longo do processo formativo. As atividades desenvolvidas por Maria junto ao seu grupo reforçam essas análises. 
Ao final do módulo 1, Maria e seu grupo preparam um vídeo para explicar as análises e conclusões obtidas para a questão de pesquisa levantada. Maria destaca na gravação a presença das variáveis e categorias em uma tabela (Figura 1).

Figura 1 - Tabela de dupla entrada construída pela professora Maria e seu grupo

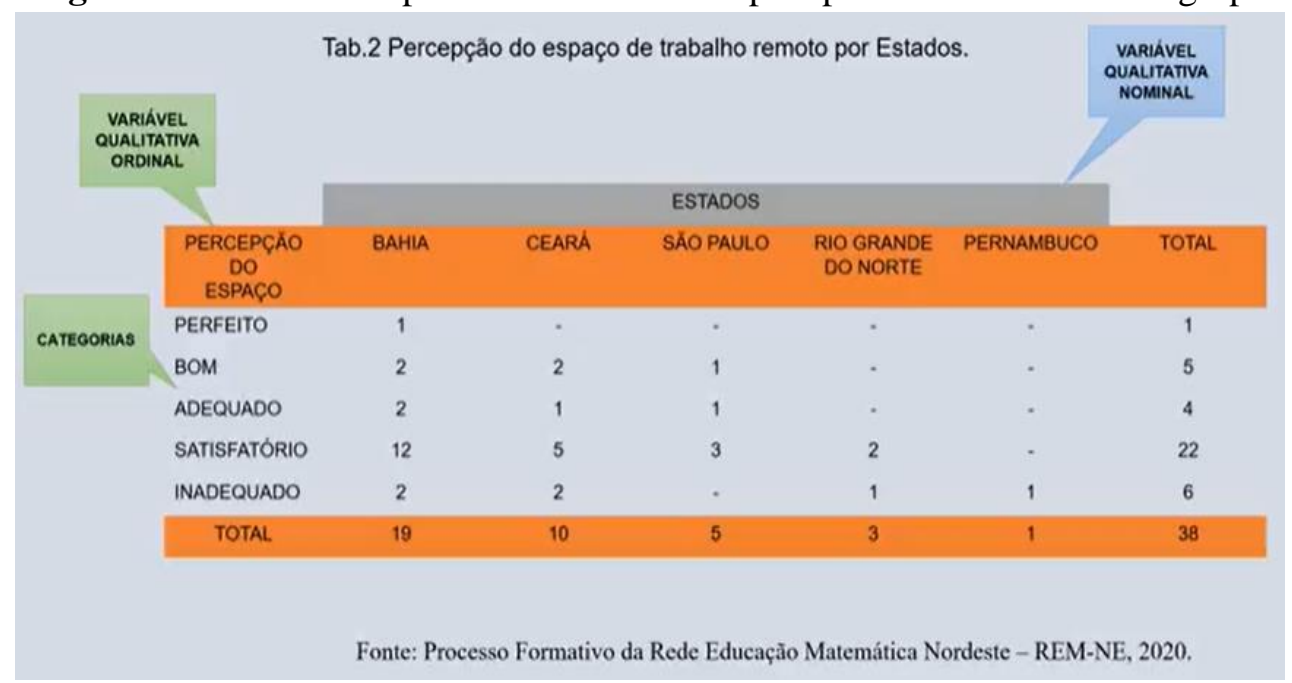

Fonte: Processo formativo Matemática \#COmVIDa/ REM-NE (2020) - Módulo 1

A Figura 1 apresenta uma tabela com a indicação de dois tipos de variáveis: qualitativa ordinal e qualitativa nominal. O grupo optou por separar as respostas relativas à percepção do espaço e os estados (Bahia, Ceará, São Paulo, Rio Grande do Norte, Pernambuco). A interpretação desse tipo de tabela requisita o cruzamento dessas duas variáveis. Castro e Castro-Filho (2018) explicam que em algumas situações é preciso comparar resultados relativos a variáveis diferentes, ou seja, fazer o cruzamento de dados, trazendo indícios do desenvolvimento do pensamento estatístico.

Verificamos ainda que o conhecimento de variável foi utilizado na construção e interpretação de tabelas e de gráficos, como será discutido em seguida.

\section{Leitura, interpretação e construção de gráficos e tabelas}

A leitura de gráficos e tabelas simples são habilidades que precisam ser desenvolvidas a partir do $1^{\circ}$ ano do Ensino Fundamental (BRASIL, 2017). Essa habilidade precisa ser trabalhada desde cedo, pois não é tão intuitiva e simples como parece. Para isso, de acordo com Cazorla et al., (2017, p. 58), o professor precisa propiciar 
a exploração das representações, sejam tabelas ou gráficos, “focando na relação entre as variáveis, nas frequências relativas, entre outros".

A formação propiciou que os professores vivenciassem um processo de análise de dados. Esse processo permitiu a construção de tabelas e de gráficos, assim como mobilizou habilidades de leitura e de interpretação dessas representações, visto que os professores precisavam discutir e depois apresentar as representações. Para representar a percepção do espaço disponível no ensino remoto para os professores que participavam da formação, o grupo de Maria construiu um gráfico de barras empilhadas (Figura 2).

Figura 2 - Gráfico de barras empilhadas construído por professora Maria e seu grupo

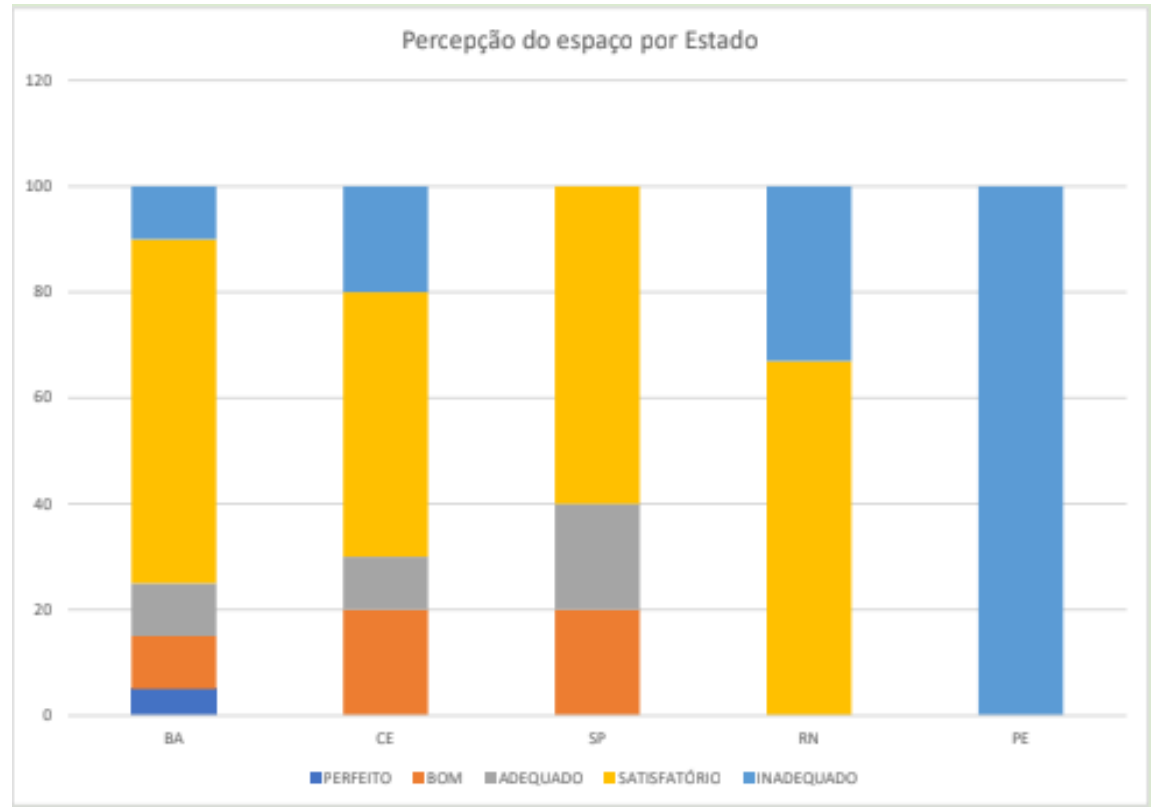

Fonte: Processo formativo Matemática \#COmVIDa/ REM-NE (2020) - Módulo 1

Na apresentação do gráfico da Figura 2, Maria explicitou sua compreensão:

Analisando os dados da variável qualitativa nominal independente, Estados, podemos inferir que na categoria estado de Pernambuco o percentual atingiu $100 \%$. Nas outras categorias dos estados: BA, CE, SP e RN, cruzadas com a categoria SATISFATÓRIO, elas aparecem com um percentual entre $50 \%$ e $65 \%$. Isto nos sinaliza que os professores apresentam, segundo os dados estatísticos que a variável qualitativa ordinal Percepção do Espaço para o trabalho remoto dos professores do REM-NE é satisfatório. Nos levando a pensar e refletir que um espaço SATISFATÓRIO é diferente de um espaço PERFEITO e BOM, onde nos dados aparecem com um percentual entre $5 \%$ a $20 \%$. Então, podemos concluir que os professores parecem não ter um espaço confortável para a realização do trabalho remoto (informação verbal). 
Conforme se observa nesse protocolo, a análise apresentada por Maria baseia-se nas variáveis, no cruzamento de variáveis e na frequência relativa, demonstrando que a interpretação mobiliza um conjunto de conhecimentos. Por isso é preciso possibilitar o desenvolvimento da compreensão de diferentes conhecimentos estatísticos, uma vez que favorece o desenvolvimento da habilidade de ler e interpretar tabelas e gráficos.

Em relação à construção de tabelas e gráficos, verificamos que Maria e seu grupo utilizou uma diversidade de representações: tabelas de dupla entrada (Figura 1 e 4), gráfico de barras empilhadas (Figura 2) e gráfico de setores (Figura 3). Castro (2012) explica que a construção de gráficos requisita conhecimentos relacionados à convenção, à classificação e à proporcionalidade.

Observa-se, na Figura 3, que as convenções necessárias ao gráfico de setores são respeitadas por Maria e seu grupo: formato circular e divisões em setores; indicação de título, fonte e legenda de cores. A classificação é categorizada em: perfeito, bom, adequado, satisfatório e inadequado; instituídas como uma variável qualitativa ordinal.

Figura 3 - Imagem de gráfico de setores construído pela professora Maria e seu grupo

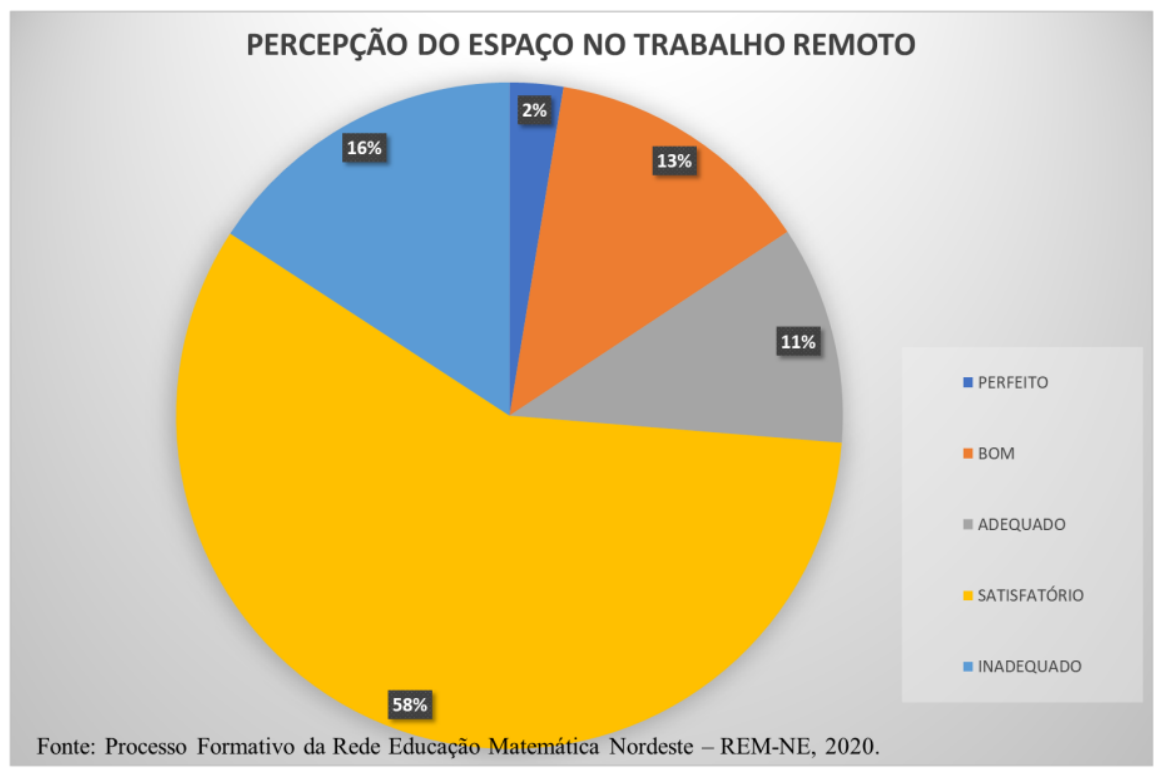

Fonte: Processo formativo Matemática \#COmVIDa/ REM-NE (2020) - Módulo 1

A proporcionalidade, determinada pela relação entre tamanho da parte e do todo, também está adequada (Figura 3). Apesar disso, não é possível concluir que Maria e seu grupo possuem o conhecimento de proporcionalidade, tendo em vista que usaram um programa para a construção do gráfico. 
Castro (2012, p. 35) explica que o uso de programas gráficos, como o usado para a construção do gráfico da Figura 3, dificulta a reflexão sobre a construção, pois os gráficos são construídos de forma automática, logo, "não exploram a compreensão dos conhecimentos matemáticos que envolvem a representação de gráficos". Isso não quer dizer que esses programas não sejam usados. Na referida situação, o programa foi importante para agilizar e proporcionar construções adequadas, a partir das reflexões do grupo, portanto teve um papel importante na análise dos dados.

Contudo, se o objetivo for a compreensão das relações proporcionais do gráfico, a construção manual pode ser mais adequada. Castro e Castro-Filho (2018) argumentam que a construção de gráficos de setores é uma atividade mais complexa, pois requer as relações da parte com o todo, ou seja, a realização de julgamentos proporcionais.

Para a conclusão, Maria e seu grupo precisaram retomar a questão de pesquisa: "Quais as condições dos professores do processo formativo do REM-NE para desenvolver suas atividades profissionais no período de isolamento social?". A retomada da questão de pesquisa permitiu que Maria chegasse a uma conclusão, conforme se observa no protocolo a seguir:

\footnotetext{
Nesse cruzamento, podemos concluir que 38 pessoas participaram dessa pesquisa, e que 22 pessoas indicaram a percepção do espaço como satisfatório; podemos dizer que o percentual dessa categoria fica em torno de 57,9\%, aparecendo também na categoria inadequado 6 participantes com o percentual de $15,8 \%$. Olhando para esses dados, podemos concluir que a percepção do espaço dos professores, entre os estados, é satisfatória, isso se faz compreender que este espaço é complexo, talvez não sendo tão confortável para o trabalho (informação verbal de Maria).
}

Cazorla et al., (2017, p. 19) explicam que a interpretação não está restrita, apenas, “a repetir as informações já contidas nas próprias medidas, mas buscam incentivar a retomada das perguntas de pesquisa que nortearam o levantamento de dados, fechando, assim, o ciclo da investigação científica”.

De acordo com a análise realizada, percebe-se que Maria e seu grupo mobilizaram um conjunto de conhecimentos estatísticos que foram necessários para a leitura, a interpretação das informações. Maria também utilizou conhecimentos relacionados à medida de tendência central, conforme será discutido na próxima seção. 


\section{Medidas de tendência central}

Ainda que a BNCC não explicite o desenvolvimento de habilidades relacionadas às medidas de tendência central nos anos iniciais do Ensino Fundamental (BRASIL, 2017), considera-se importante que o professor desenvolva essas habilidades, como forma de explorar, mesmo que de forma intuitiva, esssas medidas.

No início do Módulo 1, por meio de avaliação diagnóstica, foi possível constatar que Maria não sabia os conceitos de moda e mediana, tendo apenas efetuado o cálculo da média aritmética solicitada na situação-problema. Contudo, não é possível inferir que a docente compreenda os sentidos do conceito de média, já que não foi explicitada a estratégia de resolução ou questionamentos acerca dessa medida. Sobre isso, julgamos que a professora tenha conseguido efetuar a resolução, por tratar-se de um algoritmo previamente utilizado no cotidiano profissional.

Acerca do conceito de moda e mediana, a docente justifica sua resposta: "Não me lembro deste conteúdo" (informação textual de Maria em instrumento diagnóstico). Tal fato, explicita lacunas formativas, mesmo em conceitos considerados simples e intuitivos, como aponta Cazorla et al. (2017). Contudo, em atividades práticas durante a formação, Maria dá indícios de ganhos conceituais quanto à apreensão do conceito de moda, pois ao justificar sua análise dos dados, emprega corretamente o conceito de moda e frequência modal, conforme é possível observar na figura 4.

Figura 4 - Imagem de tabela simples construída pela professora Maria e seu grupo

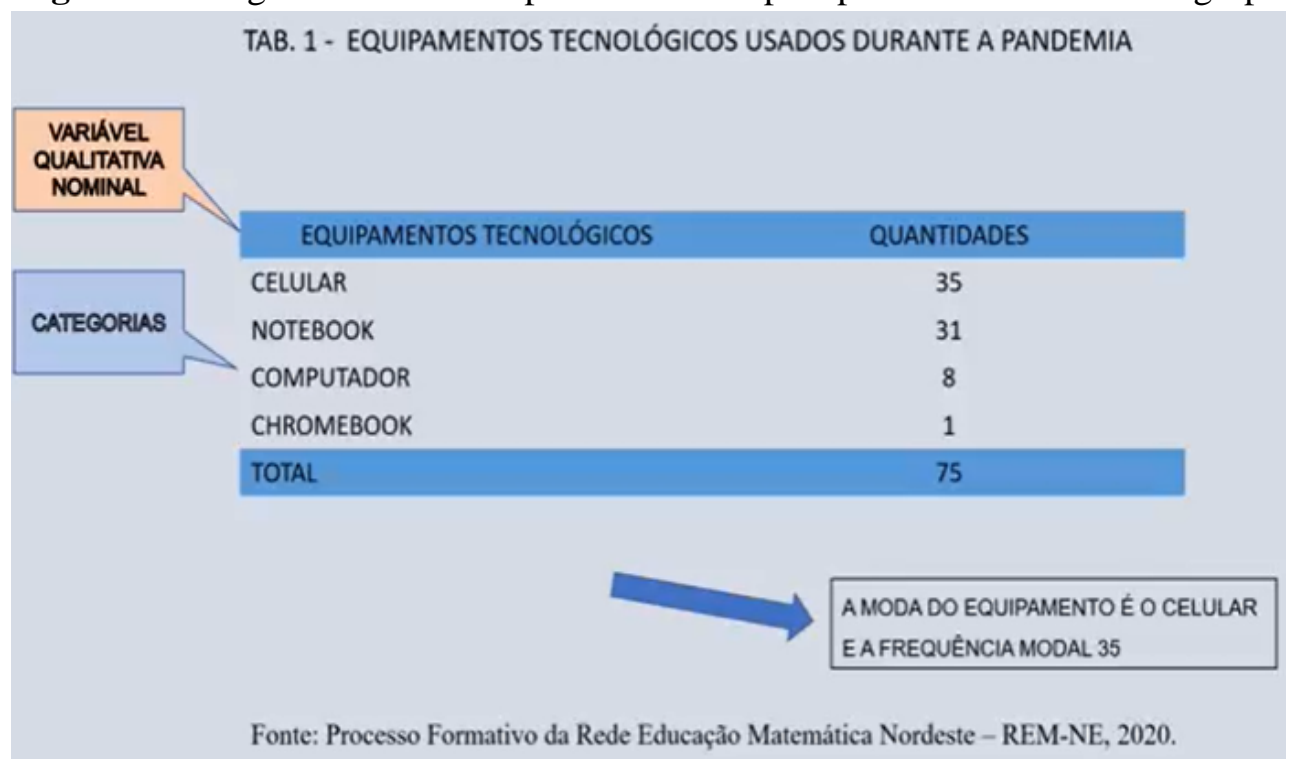

Fonte: Processo formativo Matemática \#COmVIDa/ REM-NE (2020) - Módulo 1 
Durante a explanação a professora ressalta uma análise acerca dos dados contidos na tabela acima, como é observado do excerto: "Olhando para esta tabela, a gente pode concluir que o celular é o equipamento indicado pelos professores, aqui embaixo, a moda do equipamento é o celular, porque ele aparece com a maior frequência, que nós nomeamos como frequência modal, quantidade 35" (Informação verbal de Maria apresentação do vídeo). Uma possibilidade para essa evolução deve-se ao fato de a atividade ser construída de forma colaborativa entre os professores ou ainda pela autonomia da docente na busca por materiais que subsidiaram sua percepção.

\section{Considerações Finais}

Na realização deste trabalho, buscamos analisar as reflexões e concepções de uma professora dos anos iniciais do Ensino Fundamental em relação aos conceitos estatísticos durante uma formação desenvolvida na modalidade remota. A vivência desse processo formativo permitiu que a docente vivenciasse a experiência relativa às atividades teóricas e práticas acerca de conceitos estatísticos, bem como a troca de conhecimentos e reflexões que ao final dos encontros fomentaram seu desenvolvimento profissional.

Partindo da análise de sua participação, observamos que a docente evoluiu significativamente quanto aos aspectos conceituais no que diz respeito a: compreensão de variável estatística; leitura, interpretação e construção de gráficos; percepções sobre medidas de tendência central, ainda que nessa última categoria a docente não tenha explicitado discussões sobre o conceito de mediana. Ademais, durante as discussões sobre análise e interpretação de informações, nota-se que a docente concebe percepções para além dos dados contidos nas tabelas, dando indícios do pensamento estatístico.

Destaca-se ainda o caráter colaborativo expresso nos encontros oportunizados por ferramentas tecnológicas. Nesse sentido, o ambiente suscitou reflexões acerca da aplicabilidade dos conceitos estatísticos, permitindo o acesso desses conhecimentos antes restritos a uma parcela da população. Dessa maneira inferimos que o curso contribuiu positivamente para a formação da professora, impactando em sua formação.

Para estudos futuros, pretende-se investigar conceitos que não foram discutidos, como por exemplo: fenômeno estatístico, caracterização de uma amostra estatística, bem como, as representações gráficas empregadas por outros professores cursistas. 


\section{Referências}

BATANERO, C. Didáctica de la Estadística. Granada: Universidade de Granada, 2001.

BRASIL. Ministério da Educação. Base Nacional Comum Curricular. Brasília: MEC/Secretaria de Educação Fundamental, 2017.

BRASIL. Ministério da Educação. SAEB 2017. Brasília: INEP, 2019.

CASTRO, J. B. A utilização de objetos de aprendizagem para a compreensão e construção de gráficos estatísticos. 2012. Dissertação (Mestrado em Educação) Faculdade de Educação, Programa de Pós-graduação em Educação Brasileira, Universidade Federal do Ceará, Fortaleza, 2012.

CASTRO, J. B.; CASTRO-FILHO, J. A. Desempenho de estudantes do $5^{\circ}$ ano na Construção de Gráficos de Setores: Dificuldades e Possibilidades Pedagógicas. Revista de Ensino de Ciências e Matemática (REnCiMa), v. 9, p. 12-31, 2018.

CAZORLA, I.; MAGINA, S.; GITIRANA, V.; GUIMARÃES, G. Estatística para os anos iniciais do Ensino Fundamental. Brasília: Sociedade Brasileira de Educação Matemática, 122p, 2017.

LEMOS, M. P. F. Compreensão de professores que lecionam no Ensino Fundamental sobre as medidas de tendência central. Caminhos da Educação Matemática em Revista. Aracaju, v. 9, n. 2, p. 9-29, jan. 2019.

MAGINA, S.; CAZORLA, I.; GITIRANA, V.; GUIMARÃES, G. Concepções e concepções alternativas de média: Um estudo comparativo entre professores e alunos do Ensino Fundamental. Educar em Revista, Curitiba, Brasil, n. especial 2, p. 59-72, 2010. Editora UFPR.

NACARATO, A. M. Educação continuada sob a perspectiva da pesquisa-ação: currículo em ação de um grupo de professoras ao aprender ensinando geometria. 2000, 333p. Tese (Doutorado em Educação) - Faculdade de Educação, Unicamp, Campinas, SP, 2000.

PASSOS, C. L. B. et al. Desenvolvimento Profissional do Professor que Ensina Matemática: uma meta-análise de estudos brasileiros. Quadrante, Portugal, v. XV, n. 1 e 2, p. 193-219, 2006.

PONTE, J. P. Da formação ao desenvolvimento profissional. In: ACTAS do Profmat 98. Lisboa: Associação dos Professores de Matemática, 1998. p. 27-44.

PONTES, M. M; CASTRO, J. B. A Construção do Conhecimento Matemático do Pedagogo: uma Investigação Sobre os Saberes para a Prática Pedagógica com Estatística. JIEEM, v.13, n.4, 2020. 
Reflexões e concepções de uma professora em relação à estatística, a partir de uma formação baseada no ensino remoto

RUDIO, V. F. Introdução ao projeto de pesquisa científica. 26. ed. Petrópolis: Vozes, $144 p, 2000$.

SHULMAN, L. S. Those Who Understand: Knowledge Growth in Teaching.

Educational Researcher. v.15, n.2, p. 4-14, 1986.

SILVA, E. W. F; SOUZA, E. G. Educação Estatística no contexto da formação de professores dos anos iniciais do Ensino Fundamental: mobilização dos saberes de conteúdo estatístico. Revemat, Florianópolis, v. 14, n. 1, p. 1-21, 2019.

Recebido em: 28 / 02 / 2021

Aprovado em: 16 / 04 / 2021 